\title{
Locally finite near-fields
}

\section{Susan Dancs Groves}

A near-field is locally finite if every finite subset of it generates a finite sub-near-field.

The main aim of this thesis is to give a coherent account of locally finite near-fields, including finite ones. The well known results for finite near-fields are listed and proofs are given where appropriate. The results of Zassenhaus [4] classify finite regular near-fields according to their order, $p^{2 n}$, and the order of their centres, $p^{l}$, and Lüneburg [3] has determined the number of isomorphism types within each class. A polynomial $h$ is given here which, together with the triple $p, l, n$, completely determines a finite regular near-field, up to isomorphism. The sub-near-field structure is determined in terms of these invariants and some results concerning near-field embedaings are included.

A classification of locally finite near-fields, similar to that for finite near-fields, is obtained. All locally finite near-fields (with the exception of those belonging to the seven finite irregular isomorphism types) are shown to be regular. Invariants which determine a locally finite near-field up to isomorphism are obtained - these include the invariants for finite near-fields as a special case - and the automorphism group of a locally finite near-field is determined.

Finally, a brief discussion of some possible problems is included and some information is obtained about near-fields whose multiplicative groups satisfy certain conditions.

Received 11 June 1974. Thesis submitted to the Australian National University, April 1974. Degree approved, July 1974. Supervisors: Dr M.F. Newman, Dr L.G. Kovécs. 


\section{References}

[1] Susan Dancs, "The sub-near-field structure of finite near-fields", Bull. Austral. Math. Soc. 5 (1971), 275-280.

[2] Susan Dancs, "On finite Dickson near-fields", Abh. Math. Sem. Univ. Hcomburg 37 (1972), 254-257.

[3] H. Lüneburg, "Über die Anzahl der Dickson'schen Fastkörper gegebener Ordnung", Atti del convegno di geometria combinatoria e sue applicazioni, Perugia, 1970, 319-322 (1971).

[4] Hans Zassenhaus, "Über endliche Fastkörper", Abh. Math. Sem. Hansisch. univ. 11 (1936), 187-220. 